\title{
Surgery for Intestinal Crohn's Disease: Results of a multidisciplinary approach
}

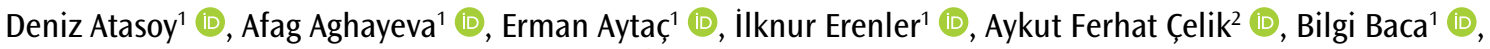
Tayfun Karahasanoğlu' (D), İsmail Hamzaoğlu' 1 (])

\section{ABSTRACT}

ORCID IDs of the authors: D.A. 0000-0002-5703-4549; A.A. $0000-0002-5317-8545$; E.A. $0000-0002-8803-0874$ I.E. 0000-0002-4878-0873; A.F.C. 0000-0001-5277-9229; B.B. 0000-0003-1704-2533; T.K. 0000-0001-9700-0450; I.H. 0000-0002-2131-3298.

\section{Cite this paper as:} Atasoy D, Aghayeva A, Aytac E, Erenler I, Çelik AF, Baca B, et al. Surgery for Intestinal Crohn's Disease: Results of a multidisciplinary approach. Turk J Surg 201834 (3): 225-228.

'Department of General Surgery, Acibadem University School of Medicine, İstanbul, Turkey

${ }^{2}$ Department of Gastroenterology, İstanbul University Cerrahpaşa School of Medicine, İstanbul, Turkey

This study was presented at the $16^{\text {th }}$ Annual Meeting of The European Society of Surgery (ESS), November 22-24, 2012, Istanbul, Turkey.

\section{Corresponding Author \\ Deniz Atasoy}

e-mail: datasoy@gmail.com

Received: 11.04.2017

Accepted: 09.08.2017

Available Online Date: 31.08 .2018

(C) Copyright 2018

by Turkish Surgical Association

Available online at

www.turkjsurg.com
Objectives: Crohn's disease is a chronic inflammatory bowel disease that requires lifelong multidisciplinary management. Seventy percent of patients affected by Crohn's disease will require at least one surgical procedure over their lifetime. The aim of this retrospective study was to present our series of patients suffering from Crohn's disease who were scheduled for surgery by a multidisciplinary team.

Material and methods: The data were retrieved from a review of 950 patients with Crohn's disease treated at our institution between March 2000 and March 2016. Only patients with intestinal Crohn's disease were included into the study. A multidisciplinary team assessed the decision to perform surgery.

Results: There were 203 patients who underwent surgery included in this study. One hundred and sixty-six were intestinal and 37 were perianal Crohn's disease. The mean age was $36 \pm 11.5$ (range, 12-75) years. Ninety-two were stricturing, 45 were fistulizing, and 12 were inflammatory. The most commonly affected site was the ileocecal region $(n=109,65.7 \%)$, and the most common surgical procedure was the ileocecal resection $(n=109,65.6 \%)$. Laparoscopic approach was the procedure of choice in $56(33.7 \%)$ patients. Of the patients enrolled, the most common early $(<30$ days) complications observed were the wound infection as the first $(n=11)$ and anastomotic leak as the second $(n=10)$. The mortality rate was $2.4 \%(n=4)$.

Conclusion: Multidisciplinary approach to Crohn's disease may decrease the surgical complications and recurrence rates leading to a better treatment.

Keywords: Crohn's disease, intestinal, multidisciplinary approach, surgical management

\section{INTRODUCTION}

Crohn's disease (CD) is a chronic inflammatory transmural bowel disease, which may present as a simple ulcerous luminal disease or a complicated fistulous, stenosing disease. The mean annual incidence of CD is 2.2 per 100.000 people in Turkey (1). Affected patients require a clinical follow-up due to risk of recurrences and long-term complications. Seventy percent of patients affected by CD will require at least one surgical procedure over their lifetime $(2,3)$. Postoperative management of CD is complex; therefore, coordination between patients, surgeons, and gastroenterologists is essential. The main treatment is medical, while surgery is reserved only for complications of the disease and treatment (3).

The aim of this retrospective study was to present our series of patients suffering from $C D$ who underwent surgery as decided by a multidisciplinary team.

\section{MATERIAL AND METHODS}

This study was performed after an approval (approval code number: 2016-12/8) was obtained from the Ethics Committee of Acibadem University, School of Medicine, Istanbul, Turkey. A retrospective chart review was conducted and informed consent was not acquired. The medical records of the patients admitted between March 2000 and March 2016 with the diagnosis of CD followed by a multidisciplinary team were analyzed. Only patients who underwent surgery were included into the study. A surgical decision was made by the final agreement of different disciplines (gastroenterology, radiology, surgery, and pathology). All procedures were performed by the same colorectal surgeons.

The patient demographics, postoperative hospital stay, medications used in the preoperative period, the American Society of Anesthesiologists score, presence of extra-intestinal disease manifestation (EIM), previous abdominal operations for CD, type of procedures, indications for resection (inflammatory, stricturing, fistulizing, or perianal CD), and postoperative complications were evaluated. All data were obtained from the patients' records.

Patients who used steroid therapy until the day before surgery, patients who received azathioprine, 6-mercaptopurine, and methotrexate within 1 month before surgery, and patients who received anti-tumor necrosis 
Table 1. Patients' characteristics and perioperative outcomes

Patients With Intestina

Crohn's Disease $(n=166)$

\begin{tabular}{lc} 
Gender* & \\
Female & $78(47)$ \\
Male & $88(53)$ \\
\hline Age\# & $36 \pm 11.5$ \\
ASA $^{*}$ & \\
I & $125(75)$ \\
II & $40(24)$ \\
III & $1(1)$ \\
\hline
\end{tabular}

\section{Disease site*}

lleocecal region

$109(66)$

Large bowel

$35(21)$

Small bowel

$11(7)$

De novo Crohn's disease

$11(7)$

$\begin{array}{lc}\text { Indication for surgery* } & \\ \text { Stricturing } & 92(55) \\ \text { Fistulizing } & 45(27) \\ \text { Inflammatory } & 12(7) \\ \text { De novo Crohn's disease } & 11(7) \\ \text { Right colon cancer } & 3(2) \\ \text { Toxic colitis } & 3(2) \\ \text { Medical treatment* } & \\ \text { AZA } & 70(42) \\ \text { Corticosteroid } & 19(12) \\ \text { Anti-TNFa } & 10(6) \\ \text { MTX } & 2(1) \\ \text { 6-MP } & 2(1) \\ \text { Non-regular (non-compliance with) } & 63(38) \\ \text { medical treatment } & \end{array}$

$\begin{array}{lc}\text { Operative approach* } & \\ \text { Open } & 104(63) \\ \text { Laparoscopic } & 56(34) \\ \text { Laparoscopic to open } & 2(1) \\ \text { Robotic } & 4(3)\end{array}$

Operative procedures*

$\begin{array}{lc}\text { lleocecal resection } & 109(65) \\ \text { Colon resection } & 35(21) \\ \text { Small bowel resection } & 11(7) \\ \text { Restorative proctocolectomy } & 11(7)\end{array}$

Early ( $<30$ day) complications*

Anastomotic leak

$10(6)$

Intra-abdominal bleeding

$2(1)$

Stoma-related complication

$2(1)$

Acute mechanical intestinal obstruction 1 (0.6)

Wound infection

Late complications*

Incisional hernia 2 (1)

Intestinal obstruction

$2(1)$

\section{Mortality*}

Renal failure

$2(1)$

Electrolyte imbalance

$1(0.6)$

Epileptic seizure

$1(0.6)$

Continuous variables are described as the mean \pm standard deviation;

categorical variables are described as $n(\%)$

ASA: American Society of Anesthesiologists; AZA: azathioprine; Anti-

TNFa: anti-tumor necrosis factor alpha; MTX: methotrexate; 6-MP:

6-mercaptopurine factor alpha within 8 weeks were regarded as under preoperative medical treatment. Patients who received immunosuppressive therapies and discontinued them at least 1 month before the surgery were regarded as "not under medical treatment." Previous surgical history was defined as having abdominal operation for CD.

The procedures were grouped into four categories: ileocecal resection, small bowel resection, colectomy, and restorative proctocolectomy (RPC). The operations were performed open, laparoscopic, or robotic. Bowel resections were either one-segment resection or more than one-segment resection. Ostomy was added depending on the operative findings (presence of intra-abdominal abscess, multiple fistulas, etc.) and patients' medical status. The ostomy was closed 2 to 3 months after the first operation.

Early complications within postoperative 30 days and longterm complications were retrieved. Early complications were divided into two types: major complications including anastomotic leak, ostomy-related complications (perforation of the ileostomy and bleeding from ileostomy), intra-abdominal hemorrhage and acute mechanical intestinal obstruction, and minor complications including wound infection.

\section{RESULTS}

For the study period, data of 950 patients were retrieved. A total of 203 patients underwent operation. Of these, 166 patients were operated on for intestinal $C D$, and 37 were operated on for perianal CD. Patient characteristics and pre- and postoperative data were shown in Table 1.

Among the enrolled patients, 78 (47\%) were women, 88 (53\%) were men with an overall mean age of $36 \pm 11.5$ (range, 12-75) years. Whereas 104 (63\%) patients had open, 56 (33.7\%) patients had laparoscopic approach. The most common indication for surgical resection was stricturing disease $(n=91,55 \%)$. Of the patients operated on, $3(1.7 \%)$ had right colon cancer, and $3(1.7 \%)$ had acute toxic colitis. Eleven (6.5\%) patients who underwent RPC were preoperatively diagnosed as ulcerative colitis, and after 2 years, they were diagnosed as de novo CD.

Recurrence was assessed by symptomatic recurrence (the presence of symptoms attributable to $C D$ that required surgical treatment). Reoperation for recurrent disease was performed in 4 (2.4\%) patients. Three patients with previously performed ileocecal resection underwent ileocolic anastomosis resection due to disease recurrence within 1 year. One patient who developed disease relapse and a history of fistulizing medically refractory $C D$ underwent multiple intestinal resections and is being followed up with short bowel syndrome.

The overall early complication rate was $15.6 \%$ (9\% major complications). Major complications were the anastomotic leak $(n=10)$, intra-abdominal bleeding $(n=2)$, complications related to ostomy $(n=2)$, and acute mechanical intestinal obstruction $(n=1)$. The early minor complication rate was $6.6 \%$, including 11 patients with wound infection. Patients diagnosed with anastomotic leakage underwent proximal intestinal diversion. Patients with intra-abdominal bleeding were operated on for hemostasis. Regarding ostomy complications, 1 patient had bleeding control surgery, and the other had stoma revision surgery. Minor complications required wet dressing or vacuum assisted closure. 
The mean postoperative hospital stay was $8.5 \pm 5.76$ (range, 2-33) days. For minimally invasive approach (laparoscopic/ robotic) group, the mean postoperative hospital stay was $8.5 \pm 6.34$ days, and for the open group, it was $9.5 \pm 5.49$ (range, 2-27) days.

In the current study, 35 (21\%) patients who underwent intestinal resections had EIMs including arthralgia in 14, ankylosing spondylitis in 4, and other EIMs in 17 (pyoderma gangrenosum, sacroileitis, uveitis, erythema nodosum, sacroileitis, etc.). Of the patients with EIMs, 8 were with colonic CD.

The long-term (>30days) complication rate was $2.4 \%(n=4)$. Two of these patients underwent laparoscopic incisional hernia repair, and the other two underwent laparoscopic adhesiolysis for intestinal obstruction. The mortality rate was $2.4 \%$ $(n=4)$. The mean follow-up time was $70 \pm 44.9$ (range, 2-194) months.

\section{DISCUSSION}

In this study, nearly one-fifth of the patients with CD were observed to require surgical treatment during their surveillance.

Once the need for a surgical intervention has been established in $C D$, surgical strategy will vary depending on the intestinal segment affected (4), on disease complications (stricture under medical treatment, uncontrolled fistulizing disease that cause abdominal abscesses, and/or electrolyte imbalance), and failed medical therapy (3). Depending on patient's general condition, severity of disease, and the involvement of intestinal segments, surgical treatment of CD may include ileocecal resection, subtotal colectomy with ileorectal anastomosis, total proctocolectomy, segmental small bowel resection, and strictureplasty (5). Stoma may be added to these procedures when necessary. In the current report, the most commonly performed surgical procedure was the ileocecal resection $(n=109,65.7 \%)$.

In this study, the symptomatic recurrence rate was $3 \%(n=5)$. Four patients developed recurrence 1 year after primary operation, and 1 patient developed recurrence 10 years after primary operation. All underwent intestinal resections. In our opinion, this low rate could be explained in terms of coordinated teamwork and careful indications for surgery. Several other reasons could also be attributed to our low symptomatic recurrence rate. First, our technique was stapled side-to-side anastomosis with two $75-80 \mathrm{~mm}$ linear staples. Thus, avoiding narrow anastomosis and fecal stasis that may trigger disease recurrence. Second, we didn't include patients with recurrent asymptomatic disease that were given medical treatment. We included only recurrent symptomatic clinical diseases that needed surgical intervention. Third, some losses to follow-up are also possible. Despite advances in the medical treatment of $C D$, clinical relapse after intestinal resection can occur in approximately $50 \%$ of the patients at 5 years $(6,7)$, and $9.5 \%$ to $43 \%$ of recurrent CD after primary resection need reoperation at 5 years $(8,9)$.

One patient with medically refractory disease in our cohort developed short bowel syndrome due to repeated intestinal resections for disease relapse at early postoperative period. She was not eligible for strictureplasty due to perforations and peritonitis. Strictureplasty has the advantage of small bowel preservation and prevention of short bowel syndrome, since $30 \%-70 \%$ of the affected patients will require repeated operations through their lifetime (3).

There were 30 patients with a history of previous abdominal operations at other centers. We were not able to retrieve the data about their previous operation details and indications. For this reason, in these patients, all previous abdominal operations were considered as operations due to $C D$. The relationship between postoperative complications and previous operations for CD is controversial. Unpublished data from our experience, although with a small number of cases, showed that previous operations did not affect the postoperative complication rates. However, Brouquet et al. (10) demonstrated that reoperation for recurrence of $C D$ was associated with an increased postoperative morbidity and a longer hospital stay than primary resection.

The incidence of EIMs in this study was $21 \%(n=35)$, and 8 of these patients had colonic CD. The most commonly recognized EIMs were abnormalities involving the axial and peripheral joints of the musculoskeletal system, which were most frequently seen when $C D$ affected the colon $(4,11)$. Our series was in line with the literature regarding the most common EIM being arthralgia ( $n=14,40 \%)$.

In our study, 2 patients developed cecal adenocarcinoma at their 8th and 9th years of the follow-up period, and 1 patient developed cecal adenocarcinoma at the 1st year of the follow-up period. Despite the controversy related to the risk of colorectal carcinoma in $C D$, an increased surveillance program is advised for these patients (3). It is recommended that, patients with $C D$ after 8 years or longer duration of chronic colitis should be enrolled in an endoscopic surveillance program (3, 4).

In our series, $36 \%$ of the surgical approaches were either laparoscopic $(n=56)$ or robotic $(n=4)$ intestinal resections. Robotic surgery has some promising advantages, and we have used this approach since December 2014, after the introduction of the robotic platform at our institution. In our current practice, we generally start with laparoscopy and continue as appropriate. In case of thickened mesentery and diffuse inflammation, the role of the laparoscopic approach in CD may be challenging (3). Riss et al. (12) stated that laparoscopic intestinal resection in CD could be performed safely in the majority of affected patients. They proposed that, even in complex cases, with all the advantages of the minimally invasive surgery, postoperative complication rate could be reduced by the laparoscopic approach.

The limitations of this study are that it is a retrospective study and that it has a relatively small-sample size.

\section{CONCLUSION}

Due to the complexity of $C D$, a combination of surgical and medical treatment is essential. Effective multidisciplinary care may improve the quality of pre- and postoperative management.

Further trials with prospective structure may elucidate the benefits of teamwork in the management of a lifelong CD. 
Ethics Committee Approval: Ethics committee approval was received for this study from the Ethics Committee of Acıbadem University School of Medicine (2016-12/8).

Informed Consent: Informed consent was not received due to the retrospective nature of the study.

Peer-review: Externally peer-reviewed.

Author Contributions: Concept - D.A., A.A., B.B.; Design - A.A., A.F.C., B.B.; Supervision - T.K., A.F.C., I.H.; Resource - A.A., A.F.C., B.B.; Materials - D.A., A.A., I.E.; Data Collection and/or Processing - D.A., A.A., A.F.C.; Analysis and/or Interpretation - D.A., A.A., I.E.; Literature Search - A.A., E.A., D.A.; Writing Manuscript - D.A., A.A., A.F.C.; Critical Reviews - B.B., A.A., A.F.C.

Conflict of Interest: The authors have no conflicts of interest to declare.

Financial Disclosure: The authors declared that this study has received no financial support.

\section{REFERENCES}

1. Tozun N, Atug O, Imeryuz N, Hamzaoglu HO, Tiftikci A, Parlak E, et al. Members of the Turkish IBD Study Group. Clinical characteristics of inflammatory bowel disease in Turkey: a multicenter epidemiologic survey. J Clin Gastroenterol 2009; 43: 51-57. [CrossRef]

2. Bernell O, Lapidus A, Hellers G. Risk factors for surgery and postoperative recurrence in Crohn's disease. Ann Surg 2000; 231: 3845. [CrossRef]

3. Shaffer VO, Wexner SD. Surgical management of Crohn's disease. Langenbecks Arch Surg 2013; 398: 13-27. [CrossRef]
4. Beck DE, Wexner SD, Hull TL, Roberts PL, Saclarides TJ, Senagore AJ, et al. The ASCRS Manual of Colon and Rectal Surgery. Second edition. 2014. [CrossRef]

5. Tekkis PP, Purkayastha S, Lanitis $S$, Athanasiou T, Heriot AG, Orchard TR, et al. A comparison of segmental vs. subtotal/total colectomy for colonic Crohn's disease: a meta-analysis. Colorectal Dis 2006; 8: 82-90. [CrossRef]

6. Hanauer SB, Korelitz BI, Rutgreets P, Peppercron MA, Thisted RA, Cohen RD, et al. Postoperative maintenance of Crohn's disease remission with 6-mercaptrourine, mesalamine, or placebo: a 2-year trial. Gastroentrology 2004; 127: 723-729. [CrossRef]

7. Alves A, Panis Y, Joly F, Pocard M, Lavergne-Slove A, Bpuhnik Y, et al. Could immunosuppressive drugs reduce recurrence rated after second resection for Crohn disease? Inflamm Bowel Dis 2004; 10: 491-495. [CrossRef]

8. Simillis C, Yamamoto T, Reese GE, Umegae $\mathrm{S}$, Mtsumoto $\mathrm{K}$, Darzi AW, et al. A meta-analysis comparing incidence of recurrence and indication for reoperation after surgery for perforating versus nonperforating Crohn's disease. Am J Gastroenterol 2008; 103: 196-205. [CrossRef]

9. Bernell O, Lapidus A, Hellers G. Risk factors for surgery and recurrence in 907 patients with primary ileocaecal Crohn's disease. $\mathrm{Br} \mathrm{J}$ Surg 2008; 87: 1697-1701. [CrossRef]

10. Brouquet A, Blanc B, Bretagnol F, Valleur P, Bouhnik Y, Panis Y. Surgery for intestinal Crohn's disease recurrence. Surgery 2010; 148: 936-946. [CrossRef]

11. Uyanikoğlu A, Akyüz F, Ermiş F, Demir K, Özdil S, Beşişik F, et al. Inflamatuvar barsak hastalığının ekstraintestinal tutulumu. Akademik Gastroentroloji Dergisi 2015; 13: 18-21.

12. Riss S, Bittermann C, Schwameis K, Kristo I, Mittlböck M, Herbst F, Stift A. Determinants for postoperative complications after laparoscopic intestinal resection for Crohn's disease. Surg Endosc 2012; 26: 933-938.[CrossRef] 